\title{
Role of Innovation in the Development of ICT Software Enterprises in Palestine
}

\author{
Imad A. Khatib \\ Renewable Energy and Environment Research Unit, Palestine Polytechnic University, Hebron, State of Palestine. \\ Email: imadk@ppu.edu
}

Received June 22 $2^{\text {nd }}, 2013$; revised July 22 ${ }^{\text {nd }}, 2013$; accepted August 22 ${ }^{\text {nd }}, 2013$

Copyright (c) 2013 Imad A. Khatib. This is an open access article distributed under the Creative Commons Attribution License, which permits unrestricted use, distribution, and reproduction in any medium, provided the original work is properly cited.

\begin{abstract}
The ICT sector in Palestine is growing in quantity and scope of works endorsed by the governmental institutions. ICT enterprises working on software development related works have started two decades ago. Some of these enterprises have scored success on national and regional levels. The ICT software development enterprises are so much important in the national innovation system as they are not only delivering goods but providing diversity of services and tools used in the process of knowledge generation and implementation and the knowledge-based-economy. In an effort of assessing the innovation levels in the Palestinian software development enterprises, the community innovation survey questionnaire has been translated, tailored and used on a representative sample. Analysis of the innovation survey questionnaire brings promising results that need to be carefully studied. It is found that most enterprises are innovators and having high potentials. However, potentials are found to be fragmented as national directive policies are not yet developed. For the development of the sector, public-private-academic partnership is needed.
\end{abstract}

Keywords: ICT Enterprises; State of Palestine; Software Development Enterprises; Community Innovation Survey

\section{Introduction}

Indicators show that the Information and communication technology (ICT) sector in Palestine has grown during the last decade. In terms of human resources, it is estimated that there are over 15,000 ICT professionals working in the different sectors; public, private, NGOs, education, etc. There are eleven Palestinian universities and five other higher education institutions that graduate around 2500 personals annually. Graduates are capable of competing in the local, regional, and international markets. In addition to universities, there are four ICT centers of excellences located in the different Palestinian districts and are considered as research incubators for ICT researchers and innovators [1].

Such potential is facing huge obstacles due to Israeli controlling of most of the Palestinian development resources. Palestinians have been continuously denied the opportunity to advance or catch up with the technological development in various areas. This has its adverse impact on the sustainable development of the national economy. Problems such as freedom of movement for people and goods across Palestinian areas are considered serious obstacles. In addition, Israeli controls of the entrances to
Palestinian areas and the natural resources within the Palestinian areas prohibit Palestinians from planning for sustainable development and force their national economy to be, directly and indirectly, linked to Israeli economy. This has created limited accessible markets to Palestinians and weakened the performance of public institutions. Electricity and water sources that are considered the backbones of the national development are totally controlled by the Israelis $[2,3]$. Similar to the energy and water, communication means are treated by Israel as a "security threat" and hence main infrastructure and facilities are Israelis, and Palestinian local communication infrastructures are directly linked to the Israelis for accessibilities.

\subsection{Development of ICT Sector in Palestine}

Since 1967, Israel had controlled the telecommunication sector in Palestinian areas and directly linked it to its telecommunication network. In 1993 the Israeli government and the Palestinian Liberation Organization have signed the Oslo Accord (Declaration of Principles) that governs the establishment of the Palestinian Authority (PA) and the followed Interim Agreement (Oslo II) [4]. Israel has considered telecommunication sector as a se- 
rious security threat and therefore, has resorted to Israeli military orders and regulations to limit the development and growth of the telecommunication, and the ICT sector as a whole. Right after the emergence of the PA in 1993, Palestinians have prepared plans to expand and improve the telecommunication infrastructure in their areas with financial and technical assistance provided by the international community and donor countries. In 1997 the PA has licensed the Palestinian telecommunication company PALTEL to provide landline and mobile phone services. The company installed the infrastructure and equipped the digital network, which currently covers more than 90\% of the Palestinian areas. Later in 1999 PALTEL established the first mobile-telecommunication company (JAWWAL) that was licensed by the PA to operate in Palestinian areas, and in 2006 the second mobile-telecommunication company ALWATANIYA was also licensed. Although the two mobile-telecommunication companies were established but Israel was still restricting the two companies' ability to update their technical infrastructure; possibly to allow creating business opportunity for Israeli ICT companies in the Palestinian areas [5].

\subsection{Existing ICT Facilities}

The Internet service is provided by PALTEL Company that provides gateways connection to Palestinian customers. However, the company does not have its own International Direct Line (IDL) gateway due to the aforementioned Israeli restrictions, and instead it uses the Israeli company's (BEZEQ) IDL.

A Palestinian company called PALNET was also established in 2004 to provide wireless services, including: Dialup/ISDN, ADSL connections, frame relays, leased line connections, web hosting, and domain name services. The latest statistical studies done by the Palestinian Central Bureau of Statistics (PCBS) show that in 2012 some $51 \%$ of the Palestinian households own personal computers (one PC at least) and that 55\% have access to computers. The same study show that more than $30 \%$ of the households have internet access [6]. The aforementioned information showed clearly how much important ICT in Palestinian development process.

\subsection{ICT Sector Enterprises}

ICT sector is nationally considered as a high priority development sector due to its direct impacts on all other development sectors. In 2004, the PA's ministerial council assigned a national committee for the preparation of the national ICT strategy, which was approved in June 2007. The main public body responsible for implementing the strategy is the Ministry of Telecommunication and Information Technology (MTIT) in cooperation with stakeholders, including higher academic institutions and the private sector. The private sector enterprises working on ICT have organized themselves institutionally in the Palestinian IT Association (PITA). The association was established in 1999 to lead the IT sector in Palestine [7]. PITA has 135 member enterprises with a diversity of ICT related specialties. Most ICT enterprises, around 55\%, are located in Ramallah city of the West Bank, and another 33\% are located in the Gaza Strip. The reason is that Ramallah city is treated currently as the temporary "political capital" of the PA and most public institutions are centralized in the city. Out of the 135 members there are 75 registered enterprises that work directly in ICT. The scopes of their work are listed in Table 1.

PITA [8] has allocated the registered ICT companies in the 12 market sectors which has identified. Table 2 shows clearly that the ICT sector is encouraged by the public sector where more than $60 \%$ of the registered companies are providing services to public institutions and central government.

Regarding the scope of services that registered ICT enterprises provide, Mercy Corp data showed that 49 enterprises identified themselves as providing software services, specifically in one of the following services:

- Software management.

- Software applications ( $3^{\text {rd }}$ party).

- Software development outsourcing.

Table 1. Scope of works of ICT companies.

\begin{tabular}{cc}
\hline Field of Work & No. of Companies \\
\hline Web Development & 29 \\
Applications & 21 \\
Telecom & 10 \\
Electronics & 16 \\
Software Services & 32 \\
Consulting & 16 \\
IT servicing & 16 \\
Other & 13 \\
\hline
\end{tabular}

Table 2. Market sector of ICT companies.

\begin{tabular}{cc}
\hline Market Sector & No. of Companies \\
\hline Manufacturing & 16 \\
Local government & 30 \\
Tourism & 19 \\
Service industry & 33 \\
Financial services & 28 \\
NGOs & 41 \\
Healthcare & 18 \\
Defense & 4 \\
Central government & 18 \\
Technology and Communications & 51 \\
Mining and Extraction & 4 \\
Education & 37 \\
\hline
\end{tabular}


The three software services provided includes the R \& $\mathrm{D}$ element but on a low profile. This is due to the fact that Palestinian institutions are lacking ICT R \& D bases, although there are some scattered joint research activities in the framework of the regional or international funded project, e.g. the European framework program 7 (FP7).

In addition, the absence of clear policies and bylaws such as the Intellectual Property Right (IPR), which is considered highly essential, discourages real investment in the ICT sector.

The emerging PA and its development depend, to a great extent, on the support and assistance provided by the international community. Until recently, donor policies have not acknowledged the ICT potential and opportunity and therefore very little fund was directed to develop this specific sector [9].

\subsection{Measuring Innovation Activities in the Private Enterprises}

In modern economy, innovation is considered the key for growth and competitiveness to both, enterprises at the corporate level and the economy at the national level. From an enterprise perspective, innovation entails the introduction of new products, processes, and services, which allows an enterprise to reduce its production costs, access new markets or develop new processes of making products. While innovation in developed countries is a system of institutions bounded by bylaws and supported by policies including the IPR, this is contrary to the case in developing countries where enterprise usually lacks such supportive policies [10]. In addition to that, enterprises in developing countries do not rely on dynamic sophisticated technology supported by R \& D process that enhances enterprises's ability to compete internationally. This adds more burden on the enterprises of the developing countries making them facing huge constraints and challenges, such as the low national per capita income, political instability, an underdeveloped infrastructure, minimal spending on $\mathrm{R} \& \mathrm{D}$, and the absence of reliable encouraging policies. However, it has been found that under such circumstances, several enterprises manage to make profits, despite the previously mentioned constraints, using business innovative ways in providing services, or manufacturing products.

It is clear that R \& D measures knowledge generation and that expenditure in terms of GDP and registered patents are primary parameters associated with innovation in R \& D. However, measuring innovation from the market side is not always linked to patent parameter. The alternative procedure enables measuring innovation from the enterprise side on quantitative and qualitative level. This is called the innovation survey method that enables collecting relevant statistical data on innovation activities and the successful introduction of different types of innovations into the market.

Innovation survey goes back to 1950s when Carter and Williams [11] have both designed and conducted an innovation survey in the UK to assess investment. Their innovation survey was further developed by Pavitt [12] and later in 1992 the OECD and Euro Statistics (EUROSTAT) formalized and standardized the instrument [13], which led to the formulation of the Oslo Manual $[14,15]$. Oslo Manual has defined innovation input and output parameters that are used to quantify innovation and based on definite parameters the Community Innovation Survey (CIS) was developed. The CIS is considered an instrument that could describe the innovation process, measure its economic weight, evaluate its effects, and identify its mechanisms (cooperation, resources, obstacles, etc) over a certain period of time. In a substantial way, CIS can produce comparable indicators based on a harmonized methodology, as a representative sample of the chosen sectors is asked to fill in the survey questionnaire. The indicators encompass different levels, from compound indicators for decision makers, to sets of indicators for general policy makers, to detailed indicators for specialists designing specific policy recommendations [16].

Since the beginning of the 1990s, several modified CIS were conducted, starting with the CIS 1, conducted in 1993 for the period of 1990-1992, followed by CIS 2, CIS 3, and later CIS 2004 and 2006, the latter covering the period of 2004-2006. Finally, the most recent CIS 2008 was conducted for the period of 2006-2008.

\section{Methodology}

\subsection{The Arabic Version of CIS}

Based on the fifth European community innovation survey [17], an Arabic version was produced without changing the innovation indicators or the measurement methodology. This is done to familiarize participating enterprises with the meaning of CIS in a language they could easily understand and hence respond with higher degree of accuracy.

The CIS has four main levels of information; the general information about the enterprise, information about product (service) innovation, information about process innovation, and information about organizational innovation. An "innovative enterprise" identified completes the CIS going to details regarding innovation activities and expenditures in each innovation activity and source of financial support if any. In addition, information on the effect of innovation activities on the enterprise in terms of market penetration, turnover, and employment should also be answered by innovative enterprise. On the partnership in innovation, the CIS seeks information the pri- 
vate-public-academic (research) partnership which is considered highly important in any national innovation system. The final level of information targets innovative and non-innovative enterprises and it tackles factors hampering innovation activities. It is worth mentioning that same Arabic version of the CIS was used to assess the innovation in two major industrial sectors in Palestine and have brought very promising results [18].

\subsection{The Representative Sample}

A representative sample of 22 ICT software companies has been identified and agreed to participate in the innovation survey study. The sample represents $29 \%$ of the ICT companies identified by Mercy Corp and around $45 \%$ of those 49 companies identified themselves as working on fields related to software. 21 of the participating companies are from the West Bank area and only 1 is located in Gaza Strip, see Figure 1. This is mainly due to the fact that most companies were adversely affected by the Israeli closure of the Gaza strip resulted in a very limited market and low accessibility. It was mentioned previously that Ramallah city is currently considered the political and economical "capital" of the Palestinian Authority and therefore, $90 \%$ of the sample are those enterprises located in Ramallah.

With facilitation provided by the PITA, enterprises identified in the sample were approached and informed about the CIS, their required input relevant to the levels of information and the importance of the provided information preciseness on the results.

The survey was administered in personal interviews by trained personals and facilitated by the MTIT and PITA. The response rate from enterprises in the representative sample scored $100 \%$.

\section{Results and Discussion}

When analyzing the 22 received questionnaires it appeared that the largest market for all participating enterprises is the local market, which includes the Israeli market due to the fact that Palestinian economy is directly

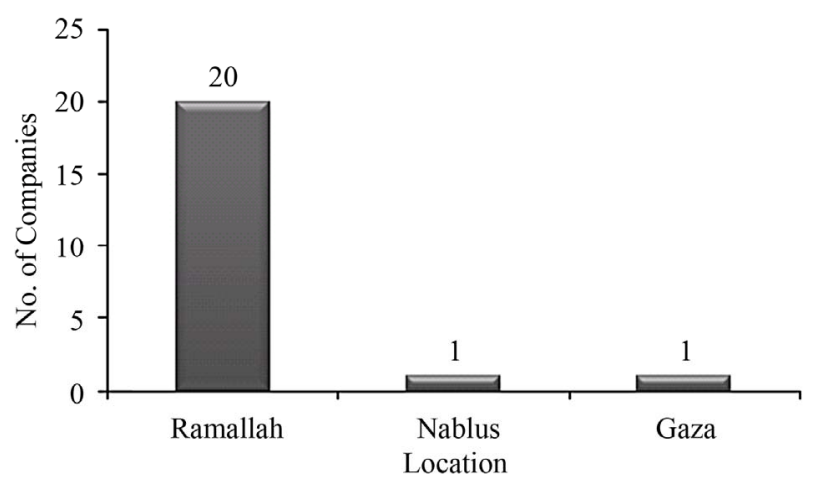

Figure 1. Locations of the ICT companies' sample. and indirectly linked to the Israeli market. Figure 2 shows also that Arab countries' market represents the second largest market, then the European market for $41 \%$ of the participating enterprises.

This is clearly relevant as major donations to PA economy come from the European countries and that the European assistance in not only financial. EU provides facilitation to Palestinian enterprises to export their products to European market in the framework of EU-PA economical agreements.

Analysis of the data showed that $91 \%$ (i.e. 20 enterprises) are services innovators and 82\% (i.e. 18 enterprises) are products innovators, as illustrated in Figure 3. This means that out of the 22 participating enterprises 20 are technological innovative enterprises.

Innovation activities on products are mainly carried out in house (Figure 4) which reflect weak level of cooperation among institutions in the national innovation system, in particular between the private sector and the academic and research one.

Figures on enterprises' expenditure in 2011 on technological innovation activities, as specified by the CIS, showed that in 2011 a total of 6 million US\$ were spent on the different innovation activities. More than $55 \%$ of the total expenditure spent in-house as a capital expenditure on buildings and equipment specifically for R \& D, while $30 \%$ are spent on the acquisition of new equipment and software.

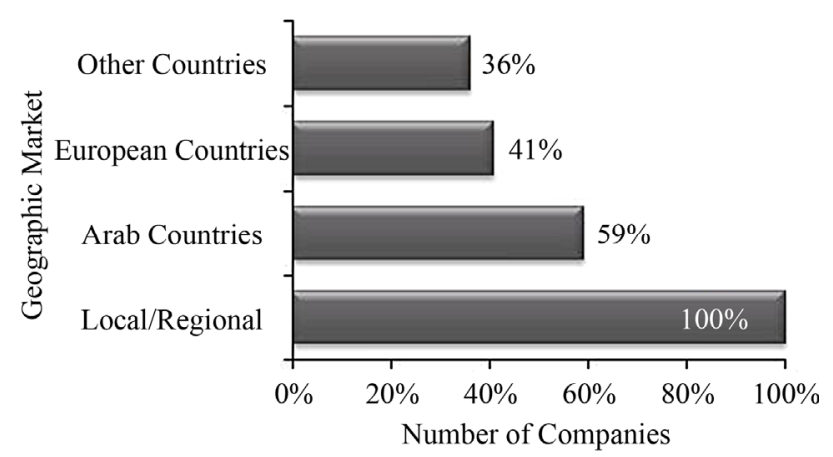

Figure 2. Extension of the geographic market of the companies.

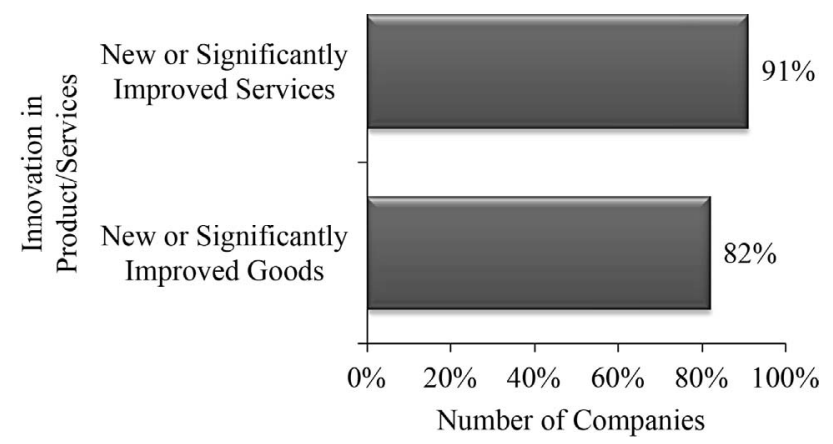

Figure 3. Technological innovative enterprises. 


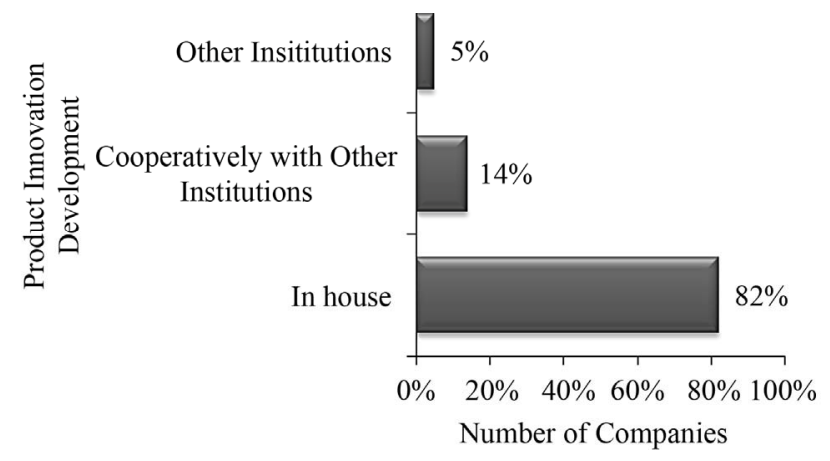

Figure 4. Product innovation development.

Expenditure on extramural R \& D is considered low as it formed $5 \%$ of the total expenditure. This again, shows that development of a national innovation system by the regulatory governmental bodies should capitalize on the potentials existed in the enterprises and the academic and research centers. A triple joint cooperation, i.e. publicprivate-academic, is a necessity in knowledge based societies. This kind of joint cooperation in the innovation systems has been suggested by, e.g. Etzkowitz [19], Carayannis and Campbell $[20,21]$, and thus by considering the ongoing policy reforms in the emerging State of Palestine, it is highly important to put policies that encourage and strengthen partnerships.

Figure 5 shows the innovation activities that enterprises where doing during 2009-2011. These information prove that enterprises where developing their capacities to compete relying on definite activities, in particular inhouse R \& D, penetration of the market with innovative ideas and human development through proper training.

Acquisition of knowledge as an innovation activity scored $60 \%$ of the total innovation activities. Source of knowledge suggested by the enterprises varies, however, less than 30\% where coming from academic and research institutions (Figure 6), a fact that needs to be addressed if a viable innovation system is to be developed.

On of the main questions in the survey that assesses the development of innovation within the enterprises is the one that concerns the identification of factors hampering innovation activities. Most enterprises suggested that cost of innovation is the most important factor as it involves high expenditure. Enterprises also agreed that innovation activities require qualified personal and that this is not easy to find. In addition, enterprises suggested that market is dominated by well established foreign enterprises which sometimes create uncertainty among national enterprises regarding market demand on innovative goods or services

\section{Conclusion}

It is clearly seen that most of the enterprises working in software development are considered technologically in-

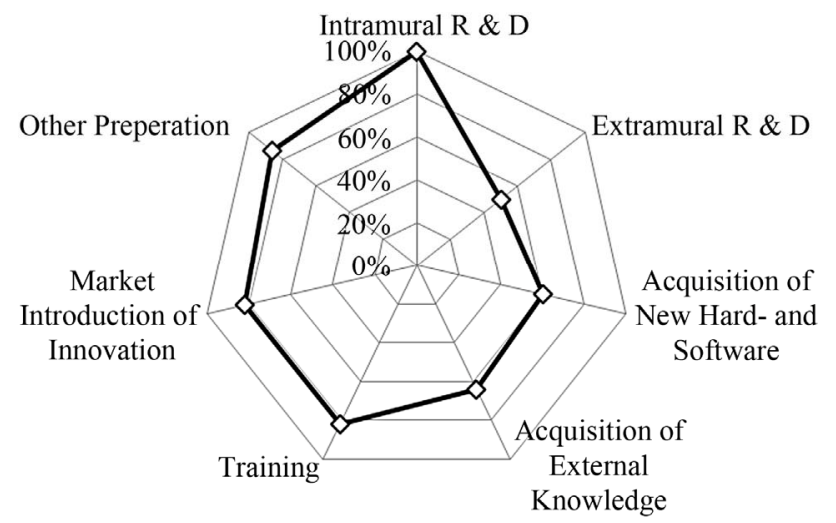

Figure 5. Innovation activities during 2009-2011.

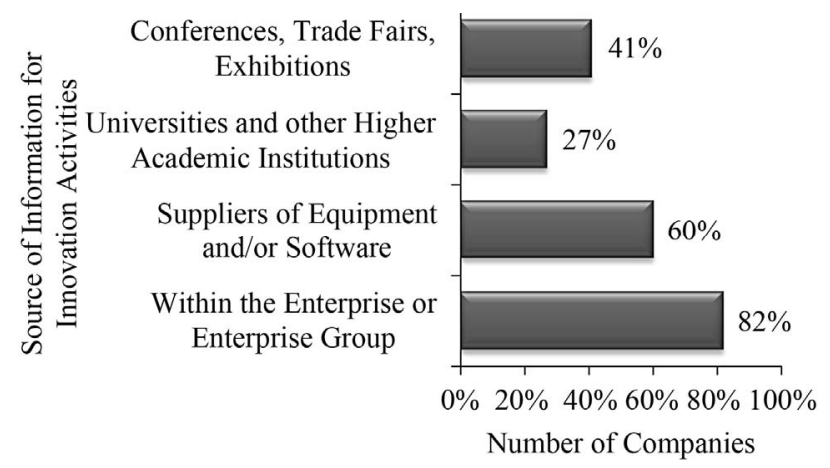

Figure 6. Knowledge source in innovation activities.

novators. However, their efforts are fragmented as the encouraging policies are still lacking. National policies should be prepared to provide an enabling environment for the enterprises to flourish and compete. This is only possible when a science, technology, and innovation policy is prepared in partnership with all national stakeholders. The policy should encourage innovation based knowledge generation and the utilization of the fragmented potentials in the private, public and academic and research sectors. An entity in transition, like Palestine, should rely on the national capabilities of building a viable economy. And only directive joint efforts will provide the chances to make a smooth transition to better economy. The software development enterprises as an economic and knowledge generating sector is so much important as it provides the facilitation and advancement tools to other sectors; private, public etc. And in that sense special attention should be paid to that sector when preparing national policies.

\section{Acknowledgements}

This research has been conducted in the framework of cooperation between the Palestine Academy for Science and Technology (PALAST), the Ministry of Telecommunication and Information Technology (MTIT) and the Palestinian IT Association (PITA). 


\section{REFERENCES}

[1] “The Palestinian Economic Bulletin,” Palestinian Economic Policy Research Institute (MAS), the Portland Trust, No. 72, September 2012.

[2] World Bank, "The Palestinian Economy and the Prospects of Its Recovery,” Economic Monitoring Report to the Ad Hoc Liaison Committee, No. 1, December 2005.

[3] World Bank, "Sustaining Achievements in Palestinian Institution-Building and Economic Growth,” Economic Monitoring Report to the Ad Hoc Liaison Committee, September 2011.

[4] "The Israeli-Palestinian Interim Agreement (Oslo II), Israeli-Palestinian Interim Agreement on the West Bank and the Gaza Strip,” Washington DC, 28 September 1995.

[5] The Portland Trust, "Palestinian Economic Bulletin," No. 34, 2009.

[6] Palestinian Central Bureau of Statistics (PSBS), "On the Eve of the International Population Day 11/07/2012,” PCBS Publications, 2012.

[7] German Society for the International Cooperation (GIZ), "Final Report: Palestinian ICT Private Sector 3-Years Strategy and Development Plan,” 2012.

[8] http://www.pita.ps/directory

[9] N. Atyani and S. Ali, "Problems of Mico, Small, and Medium Enterprises in Palestine," Palestine Economic Policy Research Institute (MAS), 2009.

[10] S. Vania, “The return of the prince of Denmark: A Survey on Recent Developments in the Economics of Innovation,” The Economic Journal, Vol. 114, No. 496, 2004, pp. F312-F332. doi:10.1111/j.1468-0297.2004.00225.x

[11] C. Carter and B. Williams, "Investment in Innovation," Oxford University Press, London, 1958.

[12] K. Pavitt, "Sectoral Patterns of Technical Change: Towards Taxonomy and a Theory," Research Policy, Vol. 13, No. 6, 1984, pp. 343-373. doi:10.1016/0048-7333(84)90018-0
[13] Organization for the Economic Cooperation and Development (OECD), “Oslo Manual,” 1st Edition, Organization for the Economic Cooperation and Development, Paris, 1992.

[14] Organization for the Economic Cooperation and Development (OECD), “Oslo Manual,” 2nd Edition, Organization for the Economic Cooperation and Development, Paris, 1996.

[15] Organization for the Economic Cooperation and Development (OECD), “Oslo Manual,” 3rd Edition, Organization for the Economic Cooperation and Development Paris, 2005.

[16] Enterprise and Industry, "European Innovation Progress Report 2008,” The European Commission, 2008.

[17] Eurostat, “The Community Innovation Survey 2008 (CIS2008), the Harmonized Survey Questionnaire,” 2008.

[18] I. Khatib, L. Tsipouri, Y. Bassiakos and A. Haj-Daoud, "Innovation in Palestinian Industries: A Necessity for Surviving the Abnormal," Journal of the Knowledge Economy, 2012. doi:10.1007/s13132-012-0093-8

[19] H. Etzkowitz, "The Triple Helix’ University-IndustryGovernment Innovation in Action,” Rutledge, New York, 2008. doi:10.4324/9780203929605

[20] E. Carayannis and D. Campbell, “'Mode 3' and 'Quadruple Helix': Toward a 21st Century Fractal Innovation Ecosystem," International Journal of Technology Management, Vol. 46, No. 3-4, 2009, pp. 201-234. doi:10.1504/IJTM.2009.023374

[21] E. Carayannis and D. Campbell, “Triple Helix, Quadruple Helix and Quintuple Helix and How Do Knowledge, Innovation and the Environment Relate to Each Other? A Proposed Framework for a Trans-Disciplinary Analysis of Sustainable Development and Social Ecology," International Journal of Social Ecology and Sustainable Development, Vol. 1, No. 1, 2010, pp. 41-69. doi:10.4018/jsesd.2010010105 